\title{
EDITORIAL
}

\section{Flexible bronchoscopy in children: an open airway}

\author{
J. Gerritsen
}

About 35 yrs ago the airways of neonates, infants and children were predominantly the working space of ear, nose and throat physicians and a sporadic paediatrician. The main indications, at that time, for rigid bronchoscopy were: aspiration of a corpus alienum, congenital web of the larynx or trachea, exploration of abnormalities of the airways, etc. This technique was only available in a limited number of institutes, and mostly in academic settings. From that time many paediatric pulmonologists learned the technique of rigid bronchoscopy at the department of E. Székely, the Pediatric Institute, Svábhegy, Budapest, Hungary [1]. This centre was specialised in rigid bronchoscopy and fluoroscopy. Back at home it was often very difficult to compete with the already existing departments.

The introduction of the special paediatric bronchoscopes, with a smaller diameter and a suction channel changed this dramatically within a period of 10-20 yrs. One of the leading publications with the challenging title: "Spelunking in the paediatric airways: Explorations with the flexible fiberoptic bronchoscope" by WoOD [2] demonstrated that this technique was useful in children and above all also safe. At that time a bronchoscope with an outside diameter of $3.5 \mathrm{~mm}$, with a $1.2 \mathrm{~mm}$ suction channel was available, and could already be applied from birth. Ever since paediatric flexible bronchoscopes have been developed with smaller diameters and most recently even with chip-technology.

At the same time paediatric pulmonology wards were being established in most universities and large hospitals. Almost all paediatric pulmonology centres nowadays have expertise in this field and gradually this technique with ultrafine bronchoscopes was also applied in prematures.

The yearly flexible bronchology courses organised by R. Wood, alternatively in the USA and in Europe, were a great success and for many paediatricians they provided the first step to becoming familiar with this technique. J. de Blic from Paris took the initiative to organise courses on flexible bronchoscopy in Europe which were supported by the Paediatric Assembly of the European Respiratory Society (ERS). The results of all these efforts and this ongoing process are presented in the publication of the ERS Task Force of the very active Bronchology Group of the Paediatric Assembly in this issue of the European Respiratory Journal [3].

Bronchoscopic techniques have especially been applied for diagnostic purposes, which are extensively discussed in the report. In addition, interventional bronchoscopy becomes more and more important in the paediatric (intensive care) ward. The limitation remains the size of the bronchoscope, especially for the application in neonates.

Bronchoscopy in infants and children has opened a new era in understanding the pathophysiology of diseases. One of the most interesting findings is the research performed in infants with cystic fibrosis (CF). In adults it had been shown that even clinically stable patients with $\mathrm{CF}$ and mild lung disease have large numbers of bacteria in their lower airways, which are accompanied by a neutrophil influx and uninhibited elastase activity [4]. Tissue damage resulting from airway inflammation has a major role in the pathogenesis of CF lung disease [5]. In pulmonary secretions from $\mathrm{CF}$ patients abundant neutrophils and increased concentrations of interleukin-8 (IL8) are found together with proteolytic neutrophil enzymes, elastase and cathepsin G [6, 7]. Airway inflammation and bacteria are already found in infants and young children with $\mathrm{CF}$ without symptoms, indicating that in this relative silent period the ongoing process of impairment of the airways starts [8]. These bronchoscopic findings were the basis of a complete change in the therapeutic approach for infants and children with this disease, and these changes can be expected to have a beneficial effect on the quality of life and survival of patients with CF.

Therapeutic interventions, using laser techniques, polyp extraction, or balloon dilatation of the airways are very specialised procedures that are seldom performed. Since the experience in these techniques is rather limited they should be restricted to large specialised centres.

In many countries research in healthy and asthmatic children using bronchoscopic techniques is still under debate. The recent discussion in Thorax underlines the differences in ethical views on this subject between Europe and Australia $[9,10]$. Bush et al. [10] stated that the scientific value of bronchoscopy and bronchial biopsies in children by no means justifies the disregard of ethical principles. Whereas the view of SLY [9] is that this research is permitted under strict conditions as stated in the Australian National Research Ethics Guidelines. I have never met children who are enthusiastic about undergoing the bronchoscopic procedure. They are not legally able to consent to their own participation in research and this consent is given on their behalf by their parents or legal guardians. The discussion concerning whether it is correct to rely on the permission given by the parents or legal guardians should be continued and must be carefully integrated in the ethical standards of the different countries. On the other hand more information on the chicken and the egg discussion about the onset of airway pathology and asthma is needed to understand whether asthma can be prevented by therapeutic intervention.

The report of the Task Force of the Scientific Group of Bronchology of the Paediatric Assembly is a useful tool in setting up paediatric bronchology wards and in standardisation of these techniques.

\section{References}

1. Székely E, Farkas E. Pediatric Bronchology. Baltimore, MD, University Park Press, 1978; pp. 1-628.

2. Wood RE. Spelunking in the pediatric airways: explorations

\footnotetext{
Correspondence: J. Gerritsen, Beatrix Children's Hospital, University Medical Centre Groningen, PO Box 30.001, 9700 RB Groningen, The Netherlands. Fax: 31 503614235. E-mail: j.gerritsen@med.rug.nl

Beatrix Children's Hospital, University Medical Centre Groningen, Groningen, The Netherlands.
} 
with the flexible fiberoptic bronchoscope. Pediatric Clin North Am 1985; 31: 785-799.

3. Midulla F, de Blic J, Barbato A, et al. Flexible endoscopy of paediatric airways. Eur Respir J 2003; 22: 698-708.

4. Konstan MW, Hilliard KA, Norvell TM, Berger M. Bronchoalveolar lavage findings in cystic fibrosis patients with stable, clinically mild lung disease suggest ongoing infection and inflammation. Am $J$ Respir Crit Care Med 1994; 150: 448-454.

5. Stockley RA. Role of inflammation in respiratory tract infections. Am J Med 1995; 99: Suppl. 6, BS8-S13.

6. Suter S, Schaad UB, Tegner H, Ohlsson K, Desgrandchamps D, Waldvogel FA. Levels of free granulocyte elastase in bronchial secretions from patients with cystic fibrosis: effect of antimicrobial therapy against Pseudomonas aeruginosa. J Infect Dis 1986; 153: 902-909.

7. Dean TP, Dai Y, Shute JK, Church MK, Warner JO Interleukin-8 concentrations are elevated in bronchoalveolar lavage, sputum and sera of children with cystic fibrosis Pediatr Res 1993; 34: 159-161.

8. Armstrong DS, Grimwood K, Carlin JB, et al. Lower airway inflammation in infants and young children with cystic fibrosis. Am Respir Crit Care Med 1997; 156: 1197-1204.

9. Sly PD. Letter to the editor. An associate editor's view. Thorax 2003; 58: 187-188.

10. Bush A, de Jongste JC, Carlsen K-H. Letter to the editor: Ultrastructural examination of bronchial specimens from children with moderate asthma. Thorax 2003; 58: 187. 